\title{
ANTROPOLOGÍA FILOSÓFICA \\ EN LOS TRATADOS DE MEDICINA SÁNSCRITA
}

\author{
PHILOSOPHICAL ANTHROPOLOGY IN \\ THE ENCICLOPAEDIAS OF SANSKRIT MEDICINE
}

\author{
JUAN ARNAU* \\ Universidad Europea de Valencia
}

RESUMEN: El artículo analiza la concepción del ser humano utilizando como fuentes primarias los compendios sánscritos clásicos de medicina de Caraka (siglo II) y Vāgbhata (siglo VII). Estos tratados combinan dos tipos de perspectivas: el punto de vista médico y trasfondos filosóficos procedentes de la escuela sāmkhya, unos de los seis sistemas filosóficos ortodoxos del brahmanismo. Se analizan las diversas concepciones en torno a la concepción del embrión, la herencia del padre y de la madre, las fases y cuidados de la gestación y el estado bicardíaco. Estas concepciones se contrastan con los trasfondos filosóficos brahmánicos que subyacen al conocimiento médico: las relaciones entre el individuo y el mundo natural, la sede de la mente, la naturaleza de la conciencia y del cuerpo sutil y las relaciones entre la salud y ciertas actitudes del cuerpo, el habla y la mente.

PALABRAS ClAVE: Ayurveda, Caraka, Vāgbhata, sāmkhya, embriología.

ABSTRACT: This article discusses the conception of the human being using the Classical Sanskrit compendiums of medicine of Caraka (2nd century) and Vāgbhata (7th century) as primary sources. These encyclopaedias combine two types of perspectives: the medical point of view and philosophical backgrounds from Sāmkhya School, one of the six orthodox philosophical systems of Brahmanism. The paper analyses the various conceptions about the conception of the embryo, the inheritance of the father and the mother, phases and care of pregnancy and the bicardiac state. These conceptions are contrasted with Brahmanic

\footnotetext{
* Dirección postal: C/Ramón Gordillo 3-3, 46010 Valencia. E-mail:arnaujuan@gmail.com
} 
philosophical backgrounds underlying medical knowledge: the relationships between the individual and the natural world, the seat of the mind, the nature of consciousness and the subtle body and the relationships between health and attitudes of the body, speech and mind.

KEYWORDS: Ayurveda, Caraka, Vāgbhata, sāmkhya, embriology.

\section{Introducción: Individuo y universo}

El Compendio de Caraka (Caraka-samhitā, ca. 150) es una de las enciclopedias médicas más antiguas de India. ${ }^{1}$ Durante siglos ha sido un almacén de conocimientos, seguramente de diversa procedencia, de las diversas tradiciones médicas del subcontinente. Su difusión e influencia del Caraka ha sido enorme, encontramos referencias a ella en las tradiciones filosóficas y literarias asociadas al brahmanismo, en la literatura budista y en las crónicas de peregrinos chinos de los primeros siglos de nuestra era. La segunda de las fuentes primarias que utilizaremos en este articulo es $L a$ esencia [de la ciencia] óctuple (Astāgahrdaya) de Vāgbhata (ca. 600), traducido con frecuencia como La esencia de la medicina, por estar ésta constituida de ocho especialidades, es probablemente la obra médica más leída en India, fundamentalmente debido a su claridad expositiva. Se ha utilizado como libro de texto para la formación de médicos a lo largo de siglos y sus numerosos comentarios y alusiones la convierten en una de las tres obras fundamentales de la literatura ayurvédica, junto a los compendios, más antiguos, de Caraka y Suśruta.

Ambos tratados suscriben la premisa antropológica según la cual el individuo es una síntesis del universo. Dicha hipótesis se considera una buena ruta para el entendimiento de la vida, tanto en su dimensión orgánica como espiritual. Esta concepción holística del cuerpo (el organismo como mundo), no impide que el organismo se considere sede de toda una serie de intercambios entre el cuerpo y su entorno. Intercambios que son efectivos precisamente por fundarse en afinidades y correspondencias que hacen posible la armonía entre sujeto y paisaje, una armonía que es el fundamento de la vida plena y saludable.

\footnotetext{
${ }^{1}$ El nombre propio Caraka (se pronuncia Charaka) se transcribe aquí siguiendo criterios normalizados internacionales para el sánscrito romanizado. Por razones tipográficas, he suprimido algunos diacríticos para facilitar la impresión del artículo, como las anusvaras de sāmkhya y samhitā (que indica el tipo de nasalización) y los diacríticos de las consonantes nasales y retroflejas (que se articulan en la región postalveolar o enrollando la lengua hasta tocar el paladar).
} 
El capítulo quinto del cuarto libro del Caraka analiza algunos de los beneficios de esta identificación del individuo con el mundo. ${ }^{2}$ Primeramente, la premisa según la cual "de lo que está hecho el hombre está hecho el mundo", constituye el fundamento de la ciencia médica, que se encargará de establecer los diferentes regímenes de intercambio a través del contorno, siempre abierto, del organismo vivo. Esos intercambios no han de entenderse exclusivamente respecto a la alimentación, los deshechos o la respiración, sino también con relación a la experiencia sensible. El abuso de la percepción causa la enfermedad, y en igual medida su infrauso. Con relación a la experiencia del habla puede decirse lo mismo. La negligencia respecto a la palabra incluye los abusos del decir, pero también los abusos en el escuchar. Respecto al pensamiento, su sobreuso se transforma en obsesión, mientras que su infrauso en "errores de juicio" (prajñāparadha), causa principal de numerosas enfermedades.

Todos los fenómenos espirituales y materiales del "mundo exterior" encuentran su correspondencia en el individuo. En primer lugar, el hombre no es sino la combinación de los cinco elementos físicos: tierra (prthvi), agua (jala), fuego (tejas), aire (vāyu), espacio $(\bar{a} k \bar{a} s \dot{s} a)$, a los que hay que añadir la presencia enigmática de la conciencia. ${ }^{3} \mathrm{El}$ comentario a esta estrofa de Cakrapāni justifica los límites y alcance de esta perspectiva. Dado que resultaría imposible enumerar todos los fenómenos del mundo (árboles, planetas, animales, etc.), así como los propios elementos que constituyen el organismo humano (ligamentos, tendones, venas, etc.), se ofrece únicamente la descripción de unos cuantos como ilustración de las afinidades entre individuo y mundo. El principio epistemológico que subyace a esta serie de correspondencias se podría enunciar así: Nadie puede entender lo que no ha experimentado por sí mismo. No es posible comprender a otro si no somos capaces de ponernos en su lugar, de identificarnos con él, de sentir como él. Esto es una forma de decir que el conocimiento no es posible sin simpatía, y que no hay simpatía sin semejanza. Si el conocimiento es posible, habrá entonces que hacer el escrutinio de las analogías, dichas semejanzas no solo serán una vía para la comprensión del mundo, sino también para asegurar la salud del cuerpo y la salvación del espíritu.

\footnotetext{
${ }^{2}$ Para las citas de los trabajos sánscritos se utilizarán las abreviaturas estándar: CS: Caraka Samhitā. SS: Suśruta Samhitā. AH: Aşţanga Hŗdayam. Para las ediciones utilizadas véase bibliografia.

${ }^{3}$ CS 4. 5. 1-4.
} 
La tierra, como el barro bíblico, da forma al hombre, el agua lo humedece, el fuego le otorga energía y calor, el aire aliento vital, el espacio porosidad, y el brahman conciencia. A continuación Caraka establece las correspondencias entre el mundo, que es aquí el mundo de la mitología brahmánica, y ciertos estados constitutivos y emocionales del individuo. ${ }^{4}$ ¿Que beneficios se siguen de esta perspectiva en el contexto de la ciencia médica? La respuesta es clara. Aquel que sabe ver la equivalencia entre universo e individuo adquiere el conocimiento verdadero. Pues tan pronto como se asume la identidad con el mundo y todas sus criaturas, se experimenta la sensación de que uno mismo es responsable de las alegrías y miserias que sobrevengan. Hombre y circunstancia se hacen uno. Esta teleología se revela como óptima tanto para la salud como para la salvación. ${ }^{5}$ Cakrapāni añade que la continuidad de la conciencia y la experiencia de la felicidad o la miseria se encuentran siempre guiadas por las acciones del pasado, y que la persona que interiorice dicho conocimiento se considerará responsable de cualquier evento o circunstancia externa, quedando libre de la atadura de los lamentos y las satisfacciones, del resentimiento y del apego. ${ }^{6}$

A continuación Caraka enumera las fases que experimenta el individuo en su desarrollo. Una causa (hetu) hace posible su manifestación, que pasa por un nacimiento, un crecimiento, una decadencia y una disolución, que se produce cuando cesa el aliento vital. Y, en sintonía con la medicina moral de la antigüedad, el apego a sus diferentes actividades constituye la causa de todas sus miserias, siendo el desapego la única fuente de felicidad. Ese desprendimiento sólo puede hacerse efectivo mediante la identificación de individuo y mundo. ${ }^{7}$ Las circunstancias siguen afectando al sujeto, pero su relación con ellas ha cambiado. El yo y las circunstancias dejan de constituir dos aspectos diferentes de la experiencia vital y pasan a considerarse una misma realidad.

\footnotetext{
${ }^{4}$ CS 4. 5. 5. Brahman se identifica con la potencialidad del alma interior, simbolizada por la mente. Indra con el sentido del yo, Āditya con la ambición, Rudra con la ira, Soma (la luna) con el placer, Vasus con la dicha, los Aśvin con la complexión, Marut con el entusiasmo, Viśvadeva con los sentidos y sus objetos, Tamas (la oscuridad) con la ignorancia, Jyoti (la luz) con el conocimiento, la evolución del mundo con el aprendizaje a lo largo de la vida, el eón Kṛta con la infancia, el eón Tretā con la juventud, el eón Dvāpara con la madurez, el eón Kali con la vejez. Cakrapāni añade que estas correspondencias son simplemente una ilustración y que podrían establecerse otras mediante las inferencias correspondientes. Por ejemplo, Bŗhaspati (el lenguaje) simboliza la mente del hombre, mientras que los Gandhārva (músicos celestiales) simbolizan sus deseos.
}

${ }^{5}$ CS 4. 5. 6-7.

${ }^{6}$ Comentario de Cakrapāni a CS 4. 5. 6-7.

${ }^{7}$ CS 4. 5. 8 . 
Las causas generales del apego son la ignorancia, el deseo, el resentimiento y la determinación, pero es posible una disección más detallada, en términos éticos y psicológicos. Entre los contribuyentes al apego se encuentran el sentido de la identidad, que consiste en identificarse con el cuerpo material y todas aquellas actividades mentales, verbales y corporales que alejan de la liberación. Entre ellas se cuentan el escepticismo frente a la verdad del karma, las dudas sobre la continuidad de la conciencia tras la muerte, la vanidad, la inclinación a la posesión de personas u objetos, la falta de discernimiento entre lo beneficioso y lo perjudicial o entre lo consciente y lo inconsciente. Finalmente también son fuente de apego todas aquellas actividades sagradas que pretenden la obtención de bienes mundanos (descendencia, riquezas): el ayuno, las oblaciones al fuego, las tres abluciones diarias, las invocaciones, las súplicas $\mathrm{y}$ otras actividades rituales que no se encuentran dirigidas hacia la liberación del individuo.

La persona carente de intelecto, paciencia y memoria, asediada por las dudas, la vanidad y la falta de discernimiento, se extravía llevada por su propio egoísmo y ceguera. Incapaz de superar las ataduras del apego (fuente de todos los males), se convierte en morada de humores malignos del cuerpo y de la mente. ${ }^{8}$ El camino de la salud se identifica así con el camino hacia la salvación, que se entiende como una forma de liberación. En ese camino destacan ciertas actitudes frente al mundo y frente a la propia conciencia, como la veracidad, la serenidad, la oportunidad y la reflexión, la consideración de todas las criaturas como aspectos de uno mismo (hay una parte de mi que es como tú), el reconocimiento de la capacidad de experimentar toda la gama de las emociones, el distanciamiento ante logros y fracasos, fortunas y calamidades, el recuerdo de la identidad del yo con el universo, ciertos hábitos ascéticos como el recogimiento, la frugalidad en las comidas y la moderación en el dormir, la confianza en las prácticas yóguicas y el optimismo ante las posibilidades del espíritu. ${ }^{9}$ Muy diversos nombres recibe dicha transformación: vidyā (ciencia), siddhi (poder), prajñ̄ $\bar{a}$ (discernimiento), medhā (capacidad de retención) y jũāna (conocimiento). ${ }^{10}$ Imaginarse

\footnotetext{
${ }^{8} \mathrm{CS}$ 4. 5. 9-10.

${ }^{9}$ CS 4. 5. 11-12.

${ }^{10}$ CS 4. 5. 19.
} 
a uno mismo diseminado en el universo y al universo sintetizado en uno mismo, permite el acceso a una sabiduría serena e indestructible. ${ }^{11}$

\section{La concepción del nuevo ser}

“Cuando, en lugar apartado, días después de la menstruación, una mujer ayunta con un hombre de otro clan, eyaculando éste una sustancia en su interior, el resultado es la concepción de un nuevo ser". ${ }^{12}$ El término sánscrito para dicha sustancia es śukra. Vāgbhata describe el esperma como blanco, denso, viscoso, dulce, espeso, semejante a la miel, el aceite y el ghee. ${ }^{13}$ Compuesto por los cuatro mahābhüta y dotado de las seis esencias o sabores (rasa). Desde un principio se establece la afinidad entre el nuevo ser y el mundo natural: la semilla de la vida lleva en sí los cuatro elementos que constituyen el mundo natural: aire, fuego, agua y tierra ( $v \bar{a} y u$, agni, jala y prthvv) , así como todas las esencias las diversas sustancias, nutritivas y medicinales, de las que se alimentará a lo largo de la vida. Cakrapāni añade que, cuando el esperma es de excelencia, los diferentes elementos participan en igual medida en su composición. Respecto a la mujer, el periodo de fertilidad (rtu) empieza a partir del dieciseisavo día desde el comienzo de la menstruación, aunque Suśruta lo sitúa en el doceavo. Se compone de doce días, los tres primeros y el onceavo no son auspiciosos. ${ }^{14}$ Después de dicho periodo, el útero se cierra como el loto al finalizar el día. ${ }^{15}$ El término sánscrito para la "semilla femenina" es ārtava, que es la palabra que designa los flujos menstruales. La unión de ambos de śukra y ārtava da lugar al embrión, pero su formación ocurre siguiendo un cierto orden, el orden establecido por las acciones pasadas del ser que va a nacer. $^{16}$

Diversos factores participan en la concepción del embrión. Tanto el esperma del padre como la semilla de la madre deben estar en óptimas condiciones. Vāgbhata recurre a la imagen del fuego que se enciende al frotar dos maderas. También juega un

\footnotetext{
${ }^{11}$ CS 4. 5. 20.

${ }^{12}$ CS 4. 2. 3.

${ }^{13} \mathrm{AH} 2.1 .17$.

${ }^{14} \mathrm{AH}$ 2. 1. 26b.

${ }^{15} \mathrm{AH}$ 2. 1. 21b.

${ }^{16} \mathrm{AH}$ 2. 1. 1.
} 
importante papel la compatibilidad "humoral", que de no existir dará lugar a malformaciones. Otro de los factores decisivos son los jugos nutritivos que alimentan al embrión y que impulsan su evolución y crecimiento. Dichas sustancias nutritivas (rasa) se derivan de la asimilación del alimento por parte de la madre. Una dieta inadecuada perjudicará gravemente el proceso de crecimiento, poniendo el peligro la vida del embrión. $^{17}$

El padre transfiere al embrión algunas características de carácter más estructural que orgánico. La forma y constitución de los huesos, uñas, dientes y cuero cabelludo, los conductos, los nervios y tendones y el semen. La madre participa en la constitución de los órganos decisivos del neonato: el corazón, los pulmones, el hígado, el bazo, los riñones, la vejiga, el recto, el estómago, el ano, el intestino grueso y delgado, así como de la piel, la carne, la grasa y el ombligo. ${ }^{18}$

Los síntomas de la concepción en la mujer incluyen salivación, pesadez, abatimiento, modorra, estremecimientos y alteraciones cardíacas. ${ }^{19}$ Cuando experimenta una tendencia natural e inconsciente a utilizar la parte izquierda de su cuerpo durante el embarazo, dará a luz una niña, si utiliza la derecha, un varón. La imaginación y los pensamientos de la madre en el momento de la concepción también resultan decisivos. El neonato se asemejará a dicho estado mental, sin que se especifique en qué sentido. El comentario de Cakrapāni subraya la influencia del factor psíquico en la concepción (la determinación que hace posible la eyaculación) y la necesidad de complacer los deseos de la madre durante el embarazo, pues de lo contrario sus inquietudes, celos o temores podrían dañar al feto. Y recomienda que la mujer que desee un niño de una determinada complexión piense e imagine países y razas donde se producen la complexión deseada.

Al margen de la importancia de los factores psíquicos, el feto se encuentra desde sus inicios constituido, como hemos mencionado, por los cuatro elementos físicos (mahābhūta). Cada uno de ellos se encuentra a su vez condicionado por cuatro factores: El factor padre, el factor madre, la dieta de la madre durante el embarazo y el factor kármico. Todos estos factores tienen su parte en la forma y desarrollo del embrión. En

\footnotetext{
${ }^{17} \mathrm{CS}$ 4. 3. 12.

${ }^{18}$ CS 4. 3. 6-7.

${ }^{19}$ CS 4. 3. 23.
} 
el caso de la alimentación de la madre, Cakrapāni añade que la dieta cae bajo la influencia de las acciones del pasado, dado que uno recibe la comida que recibe de acuerdo a la manera en que se comportó en el pasado. Y se utiliza la imagen de un árbol que crece en el lecho de un río. Del mismo modo que éste recibe los embates del agua y lo que arrastra la corriente en la época de lluvias, igualmente el embrión recibirá en el seno materno los influjos, fastos o nefastos, de los humores de la madre. ${ }^{20}$ Respecto a los parecidos de familia, si las acciones del pasado son auspiciosas, el recién nacido se asemejará a sus padres, de lo contrario será diferente.

\section{El cuerpo sutil}

Incluso si un hombre y una mujer fértiles cohabitan doce días después de la menstruación, sin la participación de la conciencia no será posible la concepción. ${ }^{21}$ El factor padre, el factor madre y la conciencia no pueden satisfacer independientemente todos los requisitos para la formación del embrión. Cada uno de ellos realiza su propia función en el proceso, y sólo mediante la convergencia de todos estos factores se produce la formación del nuevo ser. ${ }^{22}$ Nuevo en cuanto a su composición física, que obedece a las posibilidades combinatorias de los elementos físicos (bhüta), pero viejo en tanto que hereda ciertos afectos, inclinaciones y aptitudes del pasado.

En este punto la enciclopedia de Caraka se pregunta por la naturaleza y alcance del proceso de transmigración. Tradicionalmente, según la cosmovisión sāmkhya (una de las seis escuelas ortodoxas del brahmanismo), el "cuerpo sutil" es el factor que traslada las inclinaciones, disposiciones, simpatías y repulsiones, afinidades e incompatibilidades al nuevo ser, sirviendo de engarce entre las acciones de una vida pasada y los condicionamientos de la presente. Se trata más de un traslado de actitudes que de sustancias. No es tanto un alma que va de aquí para allá, penetrando sucesivamente en diferentes cuerpos, como una corriente de disposiciones (de materialidad sutil) que estructuran y dan forma a los elementos físicos (mahabhūta). La materia, por definición, es ciega e inconsciente, y lo que estas disposiciones permiten es

\footnotetext{
${ }^{20} \mathrm{CS}$ 4. 2. 29-30.

${ }^{21} \mathrm{CS}$ 4. 3. 11.

${ }^{22}$ CS 4. 3. 9.
} 
el contacto o la cercanía con el àtman que en sí no cambia ni se ve afectado por las transformaciones del mundo, pero que está presente, como testigo, en todo el proceso de la concepción. Cakrapāni subraya este aspecto. El ātman es omnipresente, no tiene sentido pues concebirlo como yendo de un cuerpo a otro, pero cuando entra en contacto con la mente (y el resto de órganos internos) forma una "entidad individual" que se trasfiere de un cuerpo a otro a través de sucesivas muertes y renacimientos. Este “cuerpo sutil" (sūksmaśārīra) es imperceptible para la mayoría de los seres (sólo los yoguis pueden advertirlo) y en este punto salen a la superficie los trasfondos filosóficos del conocimiento médico. Aunque la definición de esta enigmática entidad no coincida en todas las escuelas, los textos coinciden en que el cuerpo físico es una creación del cuerpo sutil. La combinación de la semilla del hombre y de la mujer produce el cuerpo físico del feto, pero sólo si el cuerpo sutil se incorpora a este proceso. Y es esta asociación de śukra, ārtava y sūksmaśārīra la que se encuentra condicionada por las acciones de la vida pasada. Cakrapāni propone un símil: del mismo modo que los colores de la tela dependen del color de los hilos que la forman, así las características del cuerpo físico dependerán de las características del cuerpo sutil. Y no sólo los aspectos físicos, sino que también los aspectos psíquicos se asemejan a los del cuerpo sutil.

El cuerpo sutil es el factor que "ata" los diferentes elementos que hacen posible la vida consciente y la experiencia del cuerpo. En él se recogen lo que aprehenden los sentidos y la inteligencia, que puede estar dominada por uno de los tres guņa o por una combinación de ellos, pudiendo ser luminosa, apasionada u oscura. El nuevo nacimiento se configura a partir de estas cualidades. Mentes brillantes darán lugar a seres de luz, mentes apasionadas a seres inquietos, mentes oscuras a seres sombríos. Sólo en el primer caso será posible recordar las vidas anteriores y reconocer las diferentes "asociaciones" en las que ha participado el cuerpo sutil.

La mente es aquí, tanto en las concepciones médicas del ayurveda como en las filosóficas del sāmkhya, un atributo de la conciencia. La relación que establece el cuerpo sutil con la conciencia original será la fuente de la felicidad o miseria del nuevo ser. De mismo modo que un brote no puede florecer sin la semilla, la vida no brotaría sin la presencia de la conciencia original. Ella determinará la duración de la vida, el alcance del autoconocimiento, las capacidades de la mente y de los órganos de los 
sentidos, el aliento superior y el inferior, ${ }^{23}$ la perseverancia, la apariencia, la sonoridad, la complexión, la felicidad y la miseria, el amor y el odio, la capacidad reflexiva, la constancia, la inteligencia, la memoria, el sentido de identidad y el esfuerzo. ${ }^{24}$ Vāgbhata compara la entrada del "cuerpo sutil" en el compuesto creado por la unión del semen con los flujos vaginales, con la luz del sol que, atravesando una lente, incide en un papel y lo prende. Aunque no se vean los rayos, podrá percibirse el fuego de la vida. ${ }^{25}$ En este preciso momento se inicia la vida consciente. Y el efecto de este cuerpo sutil sobre la materia tosca se compara al efecto de un molde sobre el metal fundido. Las diferentes formas del mundo natural serán consecuencia de dicho "estampado".

La ideología brahmánica se encuentra aquí muy presente. Cakrapāni afirma que el estudio, la generosidad y la meditación en una vida pasada conferirán al individuo una mente sāttvika, una mente contemplativa inclinada a la experiencia de la consciencia. En general, las mentes se hallan dominadas por rajas y tamas, por la inquietud y la inercia, y el predominio de cada uno de estos guņa establece las diferencias psíquicas y físicas entre los seres, y en ellos habrá que buscar también el origen de las enfermedades. ${ }^{26}$ Se percibe aquí una idea que domina todo el pensamiento sāmkhya: la neutralidad y pureza de la conciencia.

Todo este análisis se conecta con cuestiones etiológicas de carácter general, estableciendo las tres causas principales de las enfermedades: La primera es lo que podría llamarse error de juicio (prajñāparadha), que se encuentra relacionado con el habla y el pensamiento (qué pensamos y cómo lo pensamos, qué decimos y cómo lo decimos). En general se considera que las enfermedades no alcanzan a aquel que ha logrado la excelencia en el pensamiento, el habla y la actividad diaria. Excelencia que se presenta como una combinación de actividades devocionales, pensamiento independiente, comprensión diáfana y querencia por la meditación. Así como con el

\footnotetext{
${ }^{23}$ Cinco alientos recorren el cuerpo: El frontal (prāna), el superior (udāna), el medio (samāna), el interno (vyāna) y el inferior (upāna).

${ }^{24}$ Los atributos del embrión que dependen de la mente difieren en naturaleza y alcance de los que dependen de la conciencia original, aunque algunos de ellos se superponen. Entre ellos están la lealtad, la buena conducta, la pulcritud, la aversión, la memoria, las ilusiones vanas, el desapego, la envidia, el heroísmo, el miedo, la ira, la holgazanería, el vigor, la intensidad, la amabilidad, la profundidad, la flexibilidad.

${ }^{25} \mathrm{AH}$ 2.1. 3.

${ }^{26}$ CS 4. 2. 37-38.
} 
fomento de actitudes como el desapego, la imparcialidad, la empatía, la generosidad, la veracidad y la clemencia. ${ }^{27}$ La segunda causa principal de la enfermedad es la utilización deficiente de la experiencia sensorial, qué percibimos y cómo lo percibimos (resulta evidente que no todos vemos el mismo mundo). Y finalmente las irregularidades estacionales. Cada estación produce una excitación de los humores que será corregida en la siguiente. Todas las enfermedades pueden curarse mediante tres vías: el conocimiento correcto, la experiencia sensorial adecuada y la normalidad estacional. $^{28}$

\section{Fases y cuidados de la gestación}

Siete días después de la concepción, el embrión es sólo una masa gelatinosa (kalala) de sexo indeterminado. Durante este periodo se recomienda la realización de ciertos ritos si se desea un varón. Los ritos se entienden en este contexto como purusakāra, es decir, esfuerzos de la vida presente que pueden superar la influencia de un destino configurado por las acciones del pasado. ${ }^{29}$ La enciclopedia médica de Vāgbhata no duda en detenerse en la descripción de los diferentes rituales propiciatorios de un varón. El icono de un hombre, fabricado en oro, plata o acero, deberá calentarse al rojo vivo y sumergirse en leche. Dicha cocción se consumirá cuando el Sol se encuentre en la constelación puśya. ${ }^{30}$ También se prescribe injerir una pasta preparada con diferentes yerbas mezcladas con agua. E introducir por el orificio nasal derecho (el lado del cuerpo asociado a la masculinidad) gotas del jugo de la raíz del brhhati mezcladas con leche, haciéndolo por el izquierdo si lo que se desea es una niña.

Se recomienda que el régimen alimenticio de la mujer embarazada incluya sustancias nutritivas como la mantequilla, la leche y el ghee. ${ }^{31}$ Deberá evitar el exceso de actividad sexual, cargar cosas pesadas, cubrirse con gruesas mantas o frazadas, dormir o estar despierta a deshoras, sentarse en asientos duros o recorrer largas

\footnotetext{
${ }^{27}$ CS 4. 2. 46-47.

${ }^{28}$ CS 4. 2. 40.

${ }^{29} \mathrm{AH} 2.2 .37$

${ }^{30} \mathrm{AH}$ 2.1.38.

${ }^{31} \mathrm{AH} 2.1 .43$.
} 
distancias. También conviene evitar ciertas emociones como la pena, la ira o el miedo. Es desaconsejable suprimir las necesidades naturales, ayunar o tomar alimentos excesivamente picantes, calientes o difíciles de digerir. Tampoco es recomendable el consumo de carne o bebidas espirituosas. En general, la dieta será equilibrada. La indulgencia en alimentos que incrementan el humor vāta puede ser muy perjudicial para el feto, ocasionando ceguera $u$ otros trastornos de crecimiento como corcovas o enanismo. El exceso de alimentos que incrementan el humor pitta produce calvicie y ojos pardos, mientras que la potenciación de kapha amarillea la piel. ${ }^{32}$ Respecto a los tratamientos médicos, se evitarán las sangrías, las terapias purificatorias y los enemas hasta el octavo mes, pues podrían dañar al embrión o provocar un parto prematuro. ${ }^{33}$

Durante el primes mes de gestación el embrión no tiene una forma particular, sus órganos todavía no se han desarrollado, aunque se encuentran de forma latente. ${ }^{34}$ En el segundo mes, el embrión tiene la forma de un nódulo, redondeado y alargado. ${ }^{35}$ Es el llamado estado kalala del embrión, se produce una masa dura (ghana), si el embrión va a ser un varón, o una masa de fibras contráctiles (peśî), si va a ser mujer. En el tercer mes de embarazo surgen las cinco partes del cuerpo: la cabeza y las cuatro extremidades, y también algunas partes menores. Con la formación de la cabeza, el embrión comienza a experimentar sensaciones de placer y dolor. Un tubo conecta el ombligo del feto con el corazón de la madre y se alimenta a través de dicho conducto, "como el maizal se alimenta de las acequias". 36

La mujer embarazada debe recibir todas las atenciones. Respecto a la satisfacción de sus deseos se recomienda no dejar uno sin cumplir. El corazón del feto, que es de origen maternal, se encuentra conectado con el corazón de la madre, de modo que los deseos de la madre son en cierta medida los deseos del embrión. Ninguno debe dejar de satisfacerse, aunque no sean del todo saludables (en ese caso lo insaludable debe

\footnotetext{
${ }^{32} \mathrm{AH}$ 2.1.48.

${ }^{33}$ AH 2.1.44-47.

${ }^{34}$ CS 4. 4. 9 .

${ }^{35}$ CS 4. 4. 10.

${ }^{36} \mathrm{AH} 2.1 .54 \mathrm{~b}-56$.
} 
compensarse con dosis más grandes de lo saludable). No atender a estos antojos puede producir malformaciones en el embrión o su expulsión prematura. ${ }^{37}$

\section{La sede de la mente}

Para las tradiciones del ayurveda clásico, el corazón (hŗdaya, mahat, artha) constituye el centro del organismo y la sede de la mente. ${ }^{38}$ El corazón es además el sustrato y fundamento del resto de partes del cuerpo. Como centro de las operaciones del organismo, se encuentra conectado con el tronco, la cabeza y las extremidades, los diferentes órganos y vísceras, las facultades sensoriales y la conciencia (con sus diversos estados: dicha y miseria). Pero no todo depende del corazón, la duración de la vida así como la salud, el entusiasmo, el color y la complexión y la fuerza física y mental, dependen de ciertos hábitos saludables (sātmya) con respecto a la comida, la bebida, la actividad mental y corporal y el entorno ambiental. ${ }^{39}$

Cakrapāņi añade que aunque se considera que el corazón es el centro de la actividad mental y que la mente se conduce por el cuerpo a través ciertos conductos (manovaha), en realidad el cuerpo sensible entero es la auténtica sede de la mente, y hasta los mismos canales por los que discurre deben considerarse como la misma mente. ${ }^{40} \mathrm{Si}$ cada una de las partes del cuerpo ejerce su propia función, ello es debido al desempeño de la mente. Así se entiende la inteligencia del órgano, de cada órgano y de cada célula, por ellos transita la mente y dicha corriente mental es la que hace posible que ejerzan sus funciones.

Diez son los conductos fundamentales (mūla sirā) que arrancan del corazón y llevan la energía vital (ojas) y el pulso al resto del organismo. Son gruesos en su raíz y extremadamente finos en sus terminaciones, similares a las nervaduras de las hojas. Si tenemos en cuenta todas sus ramificaciones, se cuentan un total de setecientas venas $(\operatorname{sir} \bar{a}) .{ }^{41}$ Cien en cada pierna, treinta y dos en la pelvis, dieciséis en los costados,

\footnotetext{
${ }^{37} \mathrm{AH} 2.1 .52 \mathrm{~b}-54 \mathrm{a}$.

${ }^{38} \mathrm{CS} 1.30 .3-4$.

${ }^{39} \mathrm{AH} 2.3 .6 \mathrm{a}$.

${ }^{40}$ Comentario a CS 5. 5. 41-42

${ }^{41}$ AH 2. 3. 18-19.
} 
cuarenta y ocho en la espalda, abdomen y cuello, en el pecho cuarenta, en la mandíbula inferior dieciséis, las mismas que en la lengua, en los ojos cincuenta y seis, en la frente sesenta, en las orejas dieciséis y en el cráneo doce. De todas ellas se especifican aquellas (noventa y ocho) que no deben cortarse bajo ningún concepto. ${ }^{42}$

El corazón es indispensable para el desarrollo normal de todas las funciones físicas y mentales del organismo, toda la actividad sensorial depende de él. ${ }^{43} \mathrm{La}$ percepción sólo puede entenderse mediante la combinación del cuerpo, las facultades sensibles, la mente y la conciencia. Así, todo lo que se siente y todo lo que se experimenta depende del corazón. Cakrapāni justifica así el hecho de que sea en la región cardiaca, sede de la conciencia, donde se encuentra el objetivo de todas las prácticas yóguicas que buscan la liberación de la conciencia. ${ }^{44}$

Además, el corazón es la sede de la energía vital (ojas). El término sánscrito ojas significa fortaleza, fuerza y pujanza. En retórica es el estilo vigoroso caracterizado por el uso de largos compuestos. En el contexto médico puede traducirse como "vigor o energía vital". Ojas es aquello que mantiene y actualiza el pulso de la vida. No puede haber vida sin esta especie de "aliento vital". La perdida de ojas es la pérdida de la vida. Ojas marca el comienzo de la vida del embrión, es el fluido que lo nutre y entra en su corazón en el instante mismo de la concepción. Ojas es la esencia de todos los tejidos corporales $\left(\right.$ dhātu). ${ }^{45}$

Sobre las características específicas de esta entidad los comentaristas no se ponen de acuerdo. Algunos consideran que ojas es un elemento subsidiario de los tejidos corporales $(d h \bar{a} t u)$, en lugar de considerarlo un tejido en sí mismo. Más de un milenio después de la composición del Caraka, Cakrapāṇi agrega que no puede considerarse a ojas como una especie de esperma (śukra). De hecho, ojas es la esencia de todos los dhātu, de modo que no es diferente de ellos y tampoco puede ser considerado como un octavo dhātu. Ojas es el producto esencial que destilan los dhātu, como la miel es la esencia de frutos y flores recogida por las abejas. El comentarista distingue además dos tipos de ojas: para-ojas (el ojas por excelencia) y apara-ojas. La cantidad del primero

\footnotetext{
${ }^{42}$ AH 2. 3. 20-34.

${ }^{43}$ La actividad sensible tiene un aspecto relativo al órgano de percepción y otro relativo a la mente.

${ }^{44}$ Comentario a CS 1.30. 7.

${ }^{45}$ CS 1. 30. 9-11.
} 
es equivalente a la mitad del volumen del añjali, el espacio que queda al juntar la concavidad de ambas manos, otros afirman que consta únicamente de ocho gotas alojadas en el corazón, mientras que el apara-ojas se sitúa en los vasos adheridos a éste. Es este último tipo de ojas el que queda reducido con la diabetes, pues una reducción del primero, por pequeña que fuera, causaría la muerte. ${ }^{46}$

Cakrapāni trata de aclarar la naturaleza de esta sustancia. El ojas es además la sede donde se aloja la conciencia tras la unión del esperma y el óvulo, siendo su entrada lo que inicia la actividad cardíaca en el embrión. Así pues, ojas participa en los tres momentos decisivos de la formación del embrión, en el ya mencionado, en una segunda fase, proporcionando los nutrientes al ser naciente y en una tercera, contribuyendo a la formación de sus diferentes órganos. Y es aquí donde se justifica el apelativo de mahat, pues ojas impregna todas las evoluciones de la vida, y en ese sentido también se lo llama dhärin, "el que mantiene o soporta", porque es el factor que da la vida y la sostiene. $^{47}$

Aquellos que deseen conservar el ojas en buen estado y así prologar su vida deberán evitar toda preocupación mental, y seguir dietas equilibradas y nutritivas que ayuden a su circulación a través del cuerpo. Las actividades que contribuyan a estados serenos y contemplativos servirán fielmente a este propósito. ${ }^{48}$ Para ello se recomienda el autocontrol y una actitud empática hacia los seres vivos. ${ }^{49}$

\section{El estado bicardíaco}

Tan pronto como los órganos de los sentidos aparecen en el embrión, su mente empieza a experimentar las primeras sensaciones. A partir de ese momento, en el tercer mes de gestación, el embrión empieza a manifestar una serie de inclinaciones que son un reflejo de las experimentadas en vidas anteriores. En esta fase se inicia lo que en la literatura médica se denomina el "estado bicardíaco" (dauhrda o dvihrdaya). Un estado que supone el diálogo y la trasferencia, en un mismo organismo, de dos corazones. El

\footnotetext{
${ }^{46}$ Comentario a CS 1.30.6.

${ }^{47}$ Comentario a CS 1. 30. 9-11.

${ }^{48}$ CS 1. 30. 13-14.

${ }^{49}$ CS 1.30. 15.
} 
corazón del feto se encuentra conectado al corazón de la madre por toda una serie de conductos que facilitan el paso de los nutrientes. Estos conductos permiten además el intercambio de otras sustancias, menos identificables pero no menos poderosas: los deseos de uno y otro. Debido a esta situación, se encuentra plenamente justificada la atención y cumplimiento de los deseos de la madre, que no son sino los deseos del feto reflejados en la conciencia de su progenitora. Si se ignorarán tales deseos, la integridad del feto podría quedar dañada, ocasionando una corrupción del humor vāta que podría llegar a destruirlo. ${ }^{50}$ La protección, atención y cuidados de la madre es la protección del ser que crece en su interior. Cakrapāni confirma la tesis de que la conciencia se origina en el feto tan pronto como éste dispone de órganos sensoriales, en dicho momento se inicia la búsqueda del placer y las diferentes estrategias para evitar el dolor. ${ }^{51}$

A continuación Caraka enumera los signos y síntomas del estado bicardíaco: la interrupción de la menstruación, el exceso de salivación, la pérdida de apetito, los vómitos, el gusto por las sustancias agrias, insospechados antojos, la pesadez del cuerpo y de los ojos, el oscurecimiento de los labios y la dilatación de la vagina. ${ }^{52}$ Asimismo, se enumeran todas aquellas actividades que podría dañar al feto, como la actividad sexual violenta, el vino, la carne, la indumentaria de color rojo (que podría atraer la atención de espíritus malignos), asomarse a un pozo o cruzar la corriente de un río. ${ }^{53}$

Durante el cuarto mes todas las partes del cuerpo se hacen claramente manifiestas y durante el quinto despierta en el feto una actividad consciente ya estabilizada. Se produce un incremento en la constitución y la sangre del feto, lo que se traduce en el adelgazamiento de la madre. ${ }^{54}$ En el sexto mes va aumentando progresivamente la fuerza y la complexión, ${ }^{55}$ se forman los tendones, la venas, el pelo, las uñas y la piel. En el séptimo mes el feto ya ha adquirido las características morfológicas de la especie. ${ }^{56}$

\footnotetext{
${ }^{50}$ CS 4. 4. 19.

${ }^{51}$ CS 4. 4. 15.

${ }^{52}$ CS 4. 4. 16.

${ }^{53} \mathrm{CS} 4.4 .18$.

${ }^{54}$ CS 4. 4. 21.

${ }^{55}$ CS 4. 4. 22.

${ }^{56} \mathrm{AH}$ 2.1.57.
} 
Esta es la época más delicada para la salud de la madre. ${ }^{57}$ Los humores desarrollados por el feto y localizados en el corazón de la madre, producen en ésta picazón en las palmas de las manos, las plantas de los pies y los hombros, también aparecen marcas lineales en abdomen, muslos y pechos. En ese momento es recomendable injerir jugo de kola mezclado con mantequilla, y llevar una alimentación baja en grasas y sal, fácil de digerir y preferentemente dulce. ${ }^{58}$

Durante el octavo mes, la energía responsable de la resistencia natural del cuerpo (ojas), circula entre la madre y el feto, de modo que ambos resultan fatigados o satisfechos alternativamente. En esta época se recomienda la harina cocida con leche y sal (peyā) y condimentada con ghee. ${ }^{59}$ Dicha energía (ojas) acumulada en el feto se mueve hacia el cuerpo de la madre y regresa a través de los conductos que los unen. Esto produce estados alternativos de dicha y miseria en ambos. Cuando la energía se mueve del cuerpo del feto al cuerpo de la madre, ésta se siente exultante. Cuando recorre el camino inverso, deprimida. Lo mismo le ocurre al feto. Debido a la inestabilidad de ojas, consecuencia de la inmadurez de su cuerpo, resulta peligroso el parto durante el octavo mes. Cakrapāni apunta que los expertos recomiendan que la madre no tenga conciencia de los peligros a los que se ve sometida durante este mes, pues el miedo podría agravar el humor $v \bar{a} y u$, lo que tendría graves consecuencias. ${ }^{60} \mathrm{La}$ época del parto comienza al final del octavo mes y finaliza al final del décimo. El parto normal tiene lugar durante este periodo, aunque para Suśruta este periodo podría extenderse hasta el onceavo y doceavo mes. ${ }^{61}$ Durante el noveno mes se recomienda la comida grasa y los guisos de carne. ${ }^{62}$

Los deseos y sueños de la madre, así como las asimetrías de su cuerpo, permiten inferir el sexo del neonato. Si la leche sube primero al pecho derecho y la madre prefiere realizar sus actividades con el lado derecho del cuerpo, si tiene el abdomen elevado por ese lado, si ve en sueños objetos relacionados con la masculinidad, dará a

\footnotetext{
${ }^{57}$ CS 4. 4. 23.

${ }^{58} \mathrm{AH} 2.1 .58-60$.

${ }^{59} \mathrm{AH}$ 2.1.64.

${ }^{60}$ CS 4. 4. 24.

${ }^{61}$ CS 4. 4. 25.

${ }^{62} \mathrm{AH}$ 2.1.67.
} 
luz a un niño. Si desea la música y el baile, los perfumes y las guirnaldas, la compañía masculina y las relaciones sexuales, dará a luz a una niña. ${ }^{63}$

Una vez nacida la criatura, se establecen ciertas condiciones para el acomodo de la madre. A partir del noveno mes la madre deberá residir en el sūtikāgŗha o estancia de reposo, emplazado en un lugar auspicioso y equipado con todo lo necesario, entrando en él en un día favorable (según los astros), acompañada de matronas y expertas mujeres. ${ }^{64}$ Se recomienda la realización de ciertos rituales para proteger el parto. ${ }^{65}$ Cuando se suceden las contracciones a intervalos cortos de tiempo, la madre se recostará en un catre. Cuando el feto empieza a asomar, la vagina se dilatará, ayudada mediante la aplicación de aceites. La madre empujará suavemente al principio y después con todas sus fuerzas hasta que el bebé haya salido completamente. Entonces se la animará con palabras tales como "tu hijo ha nacido", abanicando y rociándola con agua. ${ }^{66}$

Tras el parto, si la madre siente hambre se le preparará aceite o ghee con polvo de pañcakola, seguida de melazas disueltas en agua caliente, régimen que deberá continuarse durantes dos o tres días. De este modo se reduce el humor vāta y la sangre queda purificada. $^{67}$ Después de siete días se recomienda una dieta nutritiva gradualmente incrementada, a la que se incorporará la carne después del doceavo día. Debido al esfuerzo y la descarga de flujos y sangre producidos en el parto, la madre deberá ser cuidadosamente atendida durante mes y medio. ${ }^{68}$

\section{Consideraciones en torno al problema mente-cuerpo}

Recapitulación. La conjunción del esperma, el óvulo y la conciencia hacen al embrión (garbha). ${ }^{69}$ Éste se encuentra formado por los cuatro elementos (bhūta) más el

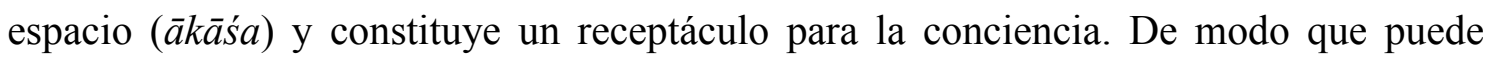

\footnotetext{
${ }^{63}$ AH 2.1.69-71.

${ }^{64}$ AH 2.1.73-74.

${ }^{65}$ AH 2.1.77.

66 AH 2.1.80-82. A continuación se enumeran algunos consejos para proceder a la extracción de la placenta (aparā) (89-91).

${ }^{67}$ AH 2.1.94-95.

${ }^{68} \mathrm{AH} 2.1 .98-100$.

${ }^{69} \mathrm{CS}$ 4. 4. 5.
} 
decirse que el elemento cognitivo constituye un sexto bhüta (aunque en sentido estricto no lo sea, pues la conciencia original es libre y sin atadura, omnipresente y omnisciente, además de inactiva y sin contenido). ${ }^{70}$

Caraka utiliza la metáfora del carro y sus diferentes piezas. Así, el embrión se forma a partir del esperma (padre), los flujos vaginales (madre), las sustancias nutritivas (rasa) y la conciencia, siendo la mente el factor que conecta todos estos elementos. ${ }^{71}$ Cakrapāni subraya que la conciencia no es un elemento más, ni el resultado de sustancias en sí mismas ciegas e inconscientes, sino el trasfondo mismo de todo el proceso, que tiene lugar gracias a la presencia del âtman. Del mismo modo que un brote de crotalaria no surge de la semilla de una palmera, así, la conciencia, no se produce a partir de los elementos físicos. El cuerpo sutil (que lleva inscrito las "relaciones" con la conciencia) se guía por las acciones de las vidas pasadas a la hora de elegir su lugar de nacimiento y será responsable de la felicidad o miseria del futuro ser. Dicha circunstancia explica además otro fenómeno: el hecho de que los hijos no siempre se parezcan a sus progenitores: el hijo de un ciego no es necesariamente ciego o un niño inteligente puede nacer de padres necios. De hecho, la experiencia sensible de todos los seres surge de la conciencia original, estando su funcionamiento y alcance aparentemente condicionado por las acciones del pasado. Hay hábitos de la percepción que tienden a la liberación, mientras que otros refuerzan las ataduras, hay percepciones evolutivas y retrógradas, aladas y subterráneas. ${ }^{72}$

Se establecen además toda una serie de correspondencias entre los cinco sentidos y los cinco elementos (los cuatro elementos más el espacio). Así, las diferentes capacidades de la experiencia sensible se entienden como modificaciones o trasformaciones de los diversos elementos. El sonido y el sentido de la audición, la ligereza y lo sutil, se asocian con el espacio (ākāśa). El tacto y el sentido de lo táctil, la aspereza y la suavidad, se vinculan al viento $(v \bar{a} y u)$. La visión y el sentido de lo visual, la luminosidad y los ardores de la digestión se asocian con el fuego (agni). El gusto, el sentido del sabor, la frialdad o la ligereza, la viscosidad y la untuosidad se vinculan al

${ }^{70}$ CS 4. 4. 6. En este punto Cakrapāni alude a la cosmología sāmkhya. Materia primordial (prakrsti) y conciencia original (purusa) son las únicas dos entidades que sobreviven tras el regreso del cosmos a su estado inmanifiesto.

${ }^{71} \mathrm{CS} 4.3 .14$

${ }^{72} \operatorname{CS} 4.3 .17$. 
agua (jala), mientras que el olor y el sentido del olfato, la dureza y la firmeza, se asocian a la tierra $(p r g t h v \vec{\imath}){ }^{73}$ ¿Y qué relación tienen estas asociaciones con la ciencia médica? Cakrapāni es explícito al respecto. Las enfermedades de la sensibilidad y de los órganos que la hacen posible deben entenderse en términos de aumento o disminución de los diferentes elementos a partir de los cuales se han desarrollado. De modo que se prescribirá la administración de sustancias en cuya composición se encuentra, de manera predominante, el elemento que compense dicho desequilibrio.

Los objetos de los sentidos se pueden agrupar en tres tipos en función de su asociación con sattva, rajas y tamas. La mente dominada por uno sólo de ellos continúa en la vida subsiguiente asociada a él. Cuando la mente del individuo se encuentra dominada por el guna sattva, ésta tendrá la capacidad de recordar las vidas pasadas. Cakrapāni añade que la presión ejercida sobre el feto cuando atraviesa el tracto genital tiene como consecuencia el olvido de las vidas pasadas. Con el esfuerzo de nacer muere el pasado y la vida se nos antoja, ilusoriamente, nueva. ${ }^{74}$

La configuración mental es responsable de los gustos, la conducta, la pureza, la memoria, el apego, la enemistad, el valor, el miedo, la ira, la modorra, el entusiasmo, la agudeza, la seriedad, la delicadeza y la inestabilidad. Cada individuo pertenece al tipo de mente por el que se haya dominado, contemplativa (sattva), pasional (rajas) u oscura (tamas). ${ }^{75}$ Aunque una misma persona puede experimentar los diferentes tipos a lo largo de su vida.

Ya se ha mencionado que Caraka define la mente como el factor que conecta la conciencia original con el cuerpo físico. Así, en la cercanía de la muerte, la mente comienza a abandonar el cuerpo, produciendo un cambio en las inclinaciones y en la conducta habitual del individuo. Los sentidos se ven afectados, la fuerza disminuye y los achaques se recrudecen. Cuando la mente abandona el cuerpo se produce el último suspiro, precisamente porque los sentidos derivan su inspiración de la mente. ${ }^{76}$

El comentario de Cakrapāni aclara algunos de los puntos oscuros del pasaje. La mente es la responsable de unir la conciencia animada (jī vâtman) con el cuerpo sutil

\footnotetext{
${ }^{73}$ CS 4. 4. 12.

${ }^{74}$ Comentario de Cakrapāni a CS 4.3.13.

${ }^{75}$ CS 4. 3. 13b.

${ }^{76}$ CS 4. 3. 13a.
} 
(ätivāhika). Este cuerpo sutil se compone de los cuatro elementos (bhūta) en su forma sutil. La mente también participa en la unión del jīvātman con el cuerpo físico. El àtman se considera omnipresente, pero el contacto con éste no es directo, si así fuera, los sentimientos y sensaciones de un individuo particular serían universales (lo que supondría una contradicción en los términos). No ocurre así, ese vínculo se establece gracias a la mediación de la mente, limitada por el cuerpo físico del individuo. Ello hace posible toda la diversidad de experiencias emocionales, todas las felicidades y miserias.

\section{Bibliografía}

Fuentes primarias:

SHARMA, Ram y Bhagwan DASH (eds.) (1976-2001). Caraka Samhitā. Sanskrit text and Critical Exposition based on Cakrapāni Datta's Āyurveda Dīpikā, Chowkhamba Sanskrit Series Office, Varanasi, 7 vols.

SHARMA, Priya (ed.) (1999-2001). Suśruta Samhitā, with Dalhana's commentary along with critical notes, Chokhambha Orientalia, New Delhi, 3 vols.

MurThY, R. Srikantha (ed.) (1991-1995). Vägbhata's Astañga Hrdayam, Chowkhamba Krishnadas Academy, Varanasi, 3 vols.

Fuentes secundarias

DASGUPTA, Surendranath (1969-1974). A History of Indian Philosophy, Cambridge University Press, Cambridge, 3 vols.

DASH, V. Bhagwan (1999). Fundamentals of Ayurvedic Medicine, Sri Satguru Publications, Delhi.

KAKAR, Sudhir (1984). Shamans, Mystics and Doctors: A Psichological Inquiry into India and its Healing traditions, Unwin, Londres.

MAJUMDAR, Asok (1998). Ayurveda: The Ancient Indian Science of Healing, Wheeler Publishing, New Delhi.

Svoboda, Robert (1992). Ayurveda: Life, Health and Longevity. Penguin, Londres.

DONIGER, Wendy (ed.) (1992). Karma and Rebirth in Classical Indian Traditions, University of California Press, Berkeley 
WUJASTYK, Dominik (1998). The Roots of Ayurveda. Selections from Sanskrit Medical Writings, Penguin, Londres.

Recibido : 9/04/ 2013

Aceptado : 28/04/2013 